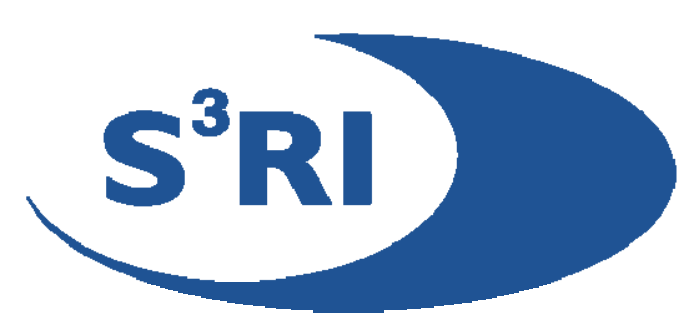

\title{
WELFARE ECONOMICS AND GIVING FOR DEVELOPMENT
}

\section{TONy AtKinson}

\begin{abstract}
The economics of welfare is at the heart of economics, but in recent decades welfare economics has been relegated to the sidelines. While economists routinely make policy recommendations, or statements about economic success or failure, they often do so without apparent awareness of the ethical foundations for their conclusions. Yet, the foundations for welfare economics are far from solid. The standard formulation imposes severe constraints on the information that is taken into account when making evaluative judgments. The adoption of a welfarist social welfare function rules out any information other than individual welfare. In this paper, I consider the implications for welfare economics of one specific issue: individual giving for world development. While giving for development is modest in total amount, it is one of the few direct ways in which individuals reveal information relevant to the properties of the social welfare function to be applied to global redistribution. I begin by examining individual motives for giving, arguing that giving for the specific purpose of development cannot be adequately explained by the standard models of "warm glow" or "public goods". An alternative is proposed, where people "frame" their giving in a way that gives meaning to their individual contribution. This alternative may well take a non-welfarist form. I go on to consider the implications for the social welfare function. What are the implications, if any, for the social welfare function of individual altruism towards people in poor countries? Finally, I address explicitly the geographical dimension, and the fact that the social welfare is a national social welfare function, which has to take into account the limited "sphere of control" of national governments.
\end{abstract}

\section{Southampton Statistical Sciences Research Institute Applications \& Policy Working Paper A07/10}

University 


\title{
Welfare Economics and Giving for Development ${ }^{1}$
}

\author{
A B Atkinson \\ Nuffield College, Oxford
}

November 2007

\section{Introduction}

The economics of welfare is at the heart of economics. We study economics, not so much for its aesthetic qualities or intrinsic interest, as for what it allows us to say about the state of society and about the case for policy choices. The study of such evaluative judgments should be central to the teaching of economics. However, in recent decades welfare economics has been relegated to the sidelines. While economists routinely make policy recommendations, or statements about economic success or failure, they often do so without apparent awareness of the ethical foundations for their conclusions. Economists use national income as a criterion for judging economic performance, or apply cost-benefit analysis, without considering the extent to which these rest on unstated assumptions. It is taken for granted that standard welfare economics provides an evaluative machinery and can answer all questions.

Yet, the foundations for welfare economics are far from solid. Welfare economics is in need, not just of oxygen, but of a make-over. As Amartya Sen has argued forcefully for many years, the standard formulation imposes severe constraints on the information that is taken into account when making evaluative judgments. As he observes in Sen (1979), public policy is conventionally assessed according to a "social welfare function", where this function is "welfarist" in the sense that social welfare depends only on the well-being of individuals. The adoption of a welfarist social welfare function rules out any information other than individual welfare. There is for example no room for direct concern with hunger or homelessness; there is no room for minimum rights. When combined with the further assumption that the social welfare function is non-decreasing in individual levels of welfare (Pareto preference), standard welfare economics allows no place for the kind of concerns about the "distance" between members of a society expressed by Plato or Tawney.

Sen has engaged in a full frontal assault on the edifice of standard welfare economics. In this paper, I adopt a different tactic. I take one concrete issue and consider its implications for welfare economics. The issue that I have chosen, as indicated by the title, is that of individual giving, specifically for world development.

\footnotetext{
${ }^{1}$ Chapter for Welfare, Development, Philosophy and Social Science: Essays for Amartya Sen's $75^{\text {th }}$ Birthday, Volume I: Welfare Economics, edited by Kaushik Basu and Ravi Kanbur. The first version was prepared for the Workshop at the Official Launch of the Oxford Poverty and Human Development Initiative, 31 May 2007 at Queen Elizabeth House, and I thank the participants for their comments. The research was supported by ESRC project grant "Giving to Development" (RES-155-25-0061), which forms part of the Non-Governmental Public Action programme. The project is being conducted in conjunction with John Micklewright, Cathy Pharoah and Sylke Schnepf. I am most grateful to them for discussion and suggestions, but they are not to be held responsible for the views expressed.
} 
While giving for development is modest in total amount, it is one of the few direct ways in which individuals reveal information relevant to the properties of the social welfare function to be applied to global redistribution. Where individuals themselves express concerns about the distribution of resources, where they are willing to make transfers, how should this be taken into account in the social welfare function? If individuals are non-welfarist in their concerns, should the state continue to adopt a welfarist social welfare function? In the first section (Section 1), I examine individual motives for giving, turning to the specific purpose of development in the second section. I then consider in Section 3 how far these motives are welfarist. In the fourth section, I go on to the implications for the social welfare function. What are the implications, if any, for the social welfare function of individual altruism towards people in poor countries? Finally, in Section 5, I address explicitly the geographical dimension, and the fact that the social welfare is a national social welfare function, which has to take into account the limited "sphere of control" of national governments.

\section{Individual Motives for Giving}

Individual transfers have been incorporated into standard welfare economics, via consideration of utility interdependence (as in Arrow, 1981). This is usually attributed to a series of contributions in 1969: Hochman and Rodgers (1969), Kolm (1969), and Winter (1969). But utility interdependence has long formed part of welfare economics (see for example, Graaff, 1963, Chapter 4), and indeed my starting point is Edgeworth's Mathematical Psychics of 1881. ${ }^{2}$ For Edgeworth, it was evident that individuals had some degree of concern for others:

"between the frozen pole of egoism and the tropical expanse of utilitarianism

[there is] the position of one for whom in a calm moment his neighbour's utility compared with his own neither counts for nothing, nor 'counts for one', but counts for a fraction" (1881, page 102).

Such a notion does of course long pre-date Edgeworth. In The Theory of Moral Sentiments, published in 1759, Adam Smith had written that "every man feels his own pleasures and his own pains more sensibly than those of other people. The former are original sensations - the latter the reflected or sympathetic images of those sensations" (1976, page 359). He goes on to consider the principles "that direct the order in which individuals are recommended to our beneficence" (1976, page 372).

Setting the position out formally, if, for person $i$ out of 1 to $n$, we write individual welfare as $u_{i}$, and individual $i$ 's objective function as $U_{i}$, then the individual is concerned with

$$
\mathrm{U}_{\mathrm{i}}=\mathrm{u}_{\mathrm{i}}+\lambda_{\mathrm{i}} \sum_{\mathrm{j} \neq \mathrm{i}} \mathrm{u}_{\mathrm{j}} /(\mathrm{n}-1)
$$

where $0 \leq \lambda_{i}<1 . \lambda_{i}$ is the fraction posited by Edgeworth, and it is assumed, for the moment, that a person is equally concerned with all his or her neighbours (I discuss below the Smithian question of the order in which individuals are "recommended to our beneficence"). This formulation is similar to that adopted by Sen (1966) in his

\footnotetext{
${ }^{2}$ I owe this to Collard (1975), who provides a very informative account of Edgeworth's treatment and its relation to more recent literature (which typically neglects Edgeworth).
} 
analysis of the allocation of labour in a co-operative enterprise where families are not necessarily indifferent to the happiness of others. In (1), the person $i$ is assumed to be concerned with his or her own welfare and, to a lesser extent, with the average welfare of others. Or, rewriting equation (1), the person is concerned with a weighted combination of own welfare and the average welfare of society:

$$
\mathrm{U}_{\mathrm{i}}=\mathrm{u}_{\mathrm{i}}\left[1-\lambda_{\mathrm{i}} /(\mathrm{n}-1)\right]+\lambda_{\mathrm{i}}[\mathrm{n} /(\mathrm{n}-1)] \sum_{\mathrm{j}} \mathrm{u}_{\mathrm{j}} / \mathrm{n}
$$

If the individual objective function takes the form described above, what form should the social welfare function take? One key issue is the way in which differences between individuals are treated - the principles of equity - but here I put this on one side, assuming that social welfare is the simple sum of individual welfares. I do this to focus on a second key issue - is social welfare a sum of $U_{i}$ or $u_{i}$ ? This may not matter. As is observed by Sen (1966), where people have the same values of $\lambda$, maximisation of the utilitarian social welfare function $\sum U_{i}$ is the same as maximising $\sum u_{i}$. But this ceases to be true if people do not treat their fellow citizens symmetrically. And when, as in the next section, we consider giving for development, asymmetry is an essential part of the story.

\section{Giving for Development}

A person with an objective such as (1) or (2) can be expected to make transfers, where these are feasible, towards others who are regarded as more deserving and whose greater deservingness outweighs the discount implied by $\lambda_{i}$ being less than 1. Motives may however be more circumscribed. The donor may be concerned, not with all his or her neighbours, but with only those who are disadvantaged. The sum in the second term may be limited to those below a poverty line, and those better off may get zero weight. (In the same way, the disadvantaged may not have reciprocal concern for the donors.) The notion of giving "for development" does indeed imply that the objective is restricted in this kind of way.

We could go even further and say that the donor has no specific concern with the individual recipients at all. Rather, as has been discussed in the literature on philanthropy (see the survey by Andreoni, 2006), the donor derives a "warm glow" from the act of making the gift. He or she "feels good" about aiding development or about relieving disaster. In the objective function, the second term is then simply a function of the amount of the gift. Such warm glow giving behaviour can readily be incorporated into standard welfare economics as a consumption externality.

The warm glow assumption might be sufficient to explain a general disposition to make charitable gifts but does not seem to capture all that lies behind giving for the specific purposes of development (Atkinson, 2007). It may explain why people make regular monthly payments to the Charities Aid Foundation (CAF) ${ }^{3}$ but not why they send their CAF cheques to Oxfam rather than cancer relief. The main alternative assumption in the literature is that donors are concerned with the end outcome, where this takes on characteristics of a "public good". If we modify the

\footnotetext{
${ }^{3}$ Individuals in the UK can make regular payments into a CAF account (to which is added the gift aid tax refund) and then decide, by writing CAF cheques, how the charitable gifts are to be allocated.
} 
earlier formulation (1) to focus on the set $D$ of disadvantaged, with $d$ members, and we introduce explicitly the gift $g_{i}$ by person i, then, taking income, $y$, as the sole argument of the utility function, the objective of person $i$ becomes

$$
\mathrm{U}_{\mathrm{i}}=\mathrm{u}\left(\mathrm{y}_{\mathrm{i}}-\mathrm{g}_{\mathrm{i}}\right)+\lambda_{\mathrm{i}} / \mathrm{d} \sum_{\mathrm{j} \varepsilon \mathrm{D}} \mathrm{u}\left[\mathrm{y}_{\mathrm{j}}+\left(\mathrm{g}_{\mathrm{i}}+\Sigma^{-}\right) / \mathrm{d}\right]
$$

The well-being of the recipients depends on their initial income, $y_{j}{ }^{4}$ and on the total of transfers divided by the number of recipients. The total of transfers is equal to $i$ 's transfer plus those made by all other donors, denoted by $\Sigma$.

This brings us to a second important feature of giving for development: the large number of potential recipients. We are not talking about a small number of neighbours but about millions of potential beneficiaries. We then encounter the problem that, as $d$ becomes large, the marginal contribution of any individual donor tends to zero. Whatever the value of $\lambda_{\mathrm{i}}$, there is a value of $d$ large enough to reduce the marginal value of an individual contribution below the cost in terms of reduced personal income. ${ }^{5}$ This gives rise to the standard free-riding problem: the individual donor has no personal incentive to contribute.

The warm glow assumption and the public goods assumption may apply in other contexts, but neither seems to capture adequately the motives for giving for development. We need, in my view, an alternative formulation. The framing of the problem suggested here is that the donor is assumed to be concerned with the impact on the living standards of the recipients; it is not enough simply to put the cheque in the envelope. But the donor does not regard the cheque as being divided among millions of recipients. The donor is assumed to "identify" with the situation of recipients on a one-to-one (or one-to- $m$, where $m$ is a small number) basis. This may be formalised as follows

$$
\mathrm{U}_{\mathrm{i}}=\mathrm{u}\left(\mathrm{y}_{\mathrm{i}}-\mathrm{g}_{\mathrm{i}}\right)+\lambda_{\mathrm{i}} \mathrm{v}\left[\left(\mathrm{y}_{\mathrm{r}}+\mathrm{g}_{\mathrm{i}}\right)\right]
$$

where $r$ denotes the representative recipient(s) envisaged by the donor, assumed to receive the whole gift. ${ }^{6}$ As written, the donor ignores the contributions of other private donors; it is assumed that they are helping other recipients. The donor wishes to make "a real difference" to the people he or she is helping, in contrast to the "spreading out" that would be indicated by measures of diminishing marginal utility.

The "framing" assumption embodied in (4) is no more than a hypothesis, but it is coherent with a number of features of present charitable activity in the development field. Such an assumption is indeed made concrete in aid programmes where donors "adopt" families or villages, to whom the transfer is channelled. Even where there is no explicit adoption, the information supplied by charities is often designed to help donors to identify with the situation of individual recipients. Moreover, charitable

\footnotetext{
${ }^{4}$ Here I am ignoring any differences in needs arising from differing family size, etc.

${ }^{5}$ The dilution by $d$ would not apply if the objective function were written in terms of the sum of the welfares of recipients, but in this case, as $d$ becomes large, so does the second term: the individual's own welfare would become entirely subsidiary. This does not seem a reasonable way to model individual giving behaviour.

${ }^{6}$ Issues of leakage (for example, through administrative costs or corruption) are not considered here, but are discussed in Atkinson (2007).
} 
agencies concentrate their activities, rather than spreading their efforts over all potential receipients. Even large charities like Oxfam have projects in a relatively small number of places.

\section{Is Giving Welfarist?}

I now assume that the motives for individual giving are those represented by the "framing" formulation (4). Such outcome-oriented giving could be welfarist, in the sense that the function $v[]$ could represent the welfare of the recipients. We would then be returning to a formulation like (1), except that in the second term the average welfare of others would be replaced by the welfare of the representative recipient. Revealed preference however suggests that donors are concerned less with achieved welfare and more with the resources to which a person has access. Donors are moved by the fact that people are living on less than $\$ 1$ a day, and this is the form adopted by governments in the Millennium Development Goals. An income of \$1 may be associated with different levels of welfare for the recipient depending on the circumstances: for example, how many hours of labour are required. The person may have to work long hours, or in unsatisfactory conditions, but these seem typically to be regarded as second-order considerations. Priority is given to ensuring an income of $\$ 1$ a day, and this is a non-welfarist objective. ${ }^{7}$ We can encompass this motive for giving by subtracting a function, $f[]$, of the poverty gap of the representative recipient

$$
U_{i}=u\left(y_{i}-g_{i}\right)-\lambda_{i} f\left[\pi-y_{r}-g_{i}\right]
$$

where $\pi$ is the poverty line, and people differ in the weight $\left(\lambda_{i}\right)$ that they attach to reducing poverty. The function $f[]$ is assumed to be increasing and to satisfy $f[0]=0$; its other properties may be influenced by the considerations discussed in Sen (1976).

Concern with an income poverty measure would represent one form of nonwelfarist objective, but it is not the only one possible. The function $v[]$ may contain a range of arguments. As has been stressed by many development economists and by the World Bank, deprivation is multi-dimensional. The Millennium Development Goals refer to hunger, to ensuring primary education, to reducing mortality, to limiting the spread of disease, and to the provision of safe drinking water. In evaluating progress towards these goals, we have a multi-dimensional scorecard. But, in order to make decisions, we have to balance one against another. As a guide to action, an incomplete ordering may not be sufficient. An individual donor has to allocate charitable donations between different uses, such as famine relief, long-term development aid, and safe water.

In balancing these different variables, the donor may be attracted by the notion of "capabilities" introduced by Sen (1980) as an alternative to the welfarist approach. Capabilities refer to the capacity of a person to do certain basic things. Sen used the example of a bicycle, which provides a person with the capability of transportation over a certain radius (and may, for instance, allow the owner to search for work). It is not the utility generated by ownership of the bicycle that is relevant; indeed, the

\footnotetext{
${ }^{7}$ The implications of such a non-welfarist objective for public policy have been examined by Kanbur, Keen and Tuomala (1994); see also Kanbur, Pirttilä and Tuomala (2006).
} 
bicycle may not in fact be used because it is considered undignified. Moreover, it is the set of options that is relevant, which raises the issue, discussed in Sen (1985), of the evaluation of such a set. At the level of the individual donor, however, a choice from such a set must be made. The donor, in entering different capabilities into the function $v[]$, is in effect prioritising the different dimensions. This remains the case, at one remove, if the gift is made to a non-governmental organisation, since the donor is choosing between different charitable agencies.

\section{The Social Welfare Function with Giving}

The objective function of the individual donor, person $i$, has been represented as possessing two elements, $U_{i}=u_{i}+\lambda_{i} v[]$, where $u_{i}$ is the individual utility and $\lambda_{i} v[]$ embodies the concern of person $i$ for the disadvantaged. We now wish to form a social welfare function that aggregates the objectives of all citizens, $i=1, \ldots, n$. Such a national social welfare function is necessary, among other reasons, to evaluate public policy towards individual giving. For example, should there be a deduction against taxable income? The tax treatment of charitable contributions has been much discussed: see Vickrey (1962), Atkinson (1976) and Diamond (2006). A national social welfare function is equally necessary to guide policy towards giving by the state in the form of Official Development Assistance. It should be noted that I focus here on a national social welfare function for a country of donors to recipients who are overseas (and therefore not included in the list of citizens $i=1, \ldots, n$ ). There will of course also be donors within the countries in which the recipients live.

How should the two elements enter the social welfare function? Different positions have been taken. The first position is simple: the social welfare function aggregates individual utilities, $u_{i}$, and ignores $\lambda_{i} v[]$ completely. This has obvious appeal in certain situations. If the second element captured negative feelings towards others, then we would have little hesitation in ignoring such feelings of jealousy. Sir Dennis Robertson dismissed such elements vigorously. Referring to the possibility that the existence of envy might make it impossible to say social welfare had increased even if everyone had more of everything, he said that we should "call in the Archbishop of Canterbury to smack people over the head if they are stupid enough to allow the increased happiness ... to be eroded by the gnawings of the green-eyed monster" (1954, page 678).

But there are also those who argue that we should ignore $\lambda_{i} v[]$ where the feelings are positive. In his recent discussion of warm glow preferences for giving for public goods, Diamond notes that "the fact that warm glows improve the description of individual behaviour does not necessarily imply that social welfare should be defined including warm glows" (2006, page 915). In part, his counter-arguments are specific to the warm glow formulation, treating it as a concern with process rather than outcome, whereas here I have adopted an outcome interpretation of giving for development. But in terms of outcomes, too, Diamond concludes that "inclusion of warm glow preferences calls for using resources to give people warm glows. Somehow this does not seem like a good use of resources" (2006, page 917). In part, this stems from the view that warm glow arises from decreasing the negative feelings associated with social pressure to donate. I agree that this form of interdependence raises interesting wider issues for welfare economics, but there are also those who 
give independently of social pressures, so that this cannot be the whole story. In part, his argument, drawing on Hammond (1987), is that inclusion of warm glow motives is double counting, since enjoyment of the public good by others is already included in the social welfare function. In the present case, however, there is no double counting since the recipients are assumed to be in a different country. The only way in which they can enter is via the term $\lambda_{i} v[]$.

In the case of giving for development, therefore, we cannot, in my view, simply dismiss the concerns expressed by individuals (the term $\lambda_{i} v[]$ ). One consequence is that the social welfare function could well become non-welfarist. As argued earlier, donors may well be concerned with income poverty irrespective of other circumstances, such as hours of work. In that case, a social welfare function formed by summing the individual objective functions ${ }^{8}$ would be $\Sigma u_{i}$ minus a function of the representative poverty gap weighted by the average value of $\lambda$. If the concerns of donors are multi-dimensional, or are based on capabilities, the inclusion of the terms $\lambda_{i} v[]$ will modify the social welfare function more radically.

This brings me to a more fundamental issue. If individuals evaluate the outcome of giving in a non-welfarist manner, should this not affect the way in which we form the social welfare function? If individuals are concerned with development in terms of capabilities, then we have to consider why we are evaluating the performance of our own society in a different way (aggregating individual welfares). One response may be to say that individual giving is a minor part of economic activity (in 2005/2006 the average amount given per head in the UK was $£ 2.04$ a month (NCVO and CAF, 2006, page 29)). The tail would be wagging the dog. But individual giving is one of the few direct ways in which individuals reveal information relevant to the properties of the social welfare function, and this information should not be simply dismissed.

\section{Spheres of Control and Giving by Individuals and by Nations}

If the government of a country were to adopt a global cosmopolitan social welfare function, including all world citizens, then the discussion above would need to be modified, but governments do not frame their objectives in this way. In part this is because of the limited sphere of control of national governments. The government of a country can seek to influence the governments of other countries, and their citizens, but it has no direct control. In some respects, the effect is similar to that of political or second-best constraints on social welfare maximisation within a country. In his paper on "control areas", Sen described the planner as "part of a political machinery and [as] constrained by a complex structure within which he has to operate" (1972, page 486). As I have argued elsewhere (1995), one has to combine welfare economics and political economy.

The notion of sphere of control has however wider implications. It does not just impose constraints on the achievement of maximum social welfare, but enters

\footnotetext{
${ }^{8}$ I restrict attention to summation, as I do not want to enter the difficulties that arise when we consider the distribution of $U_{i}$, which would involve comparing the values for people with differing values of $\lambda_{i}$. These difficulties are illustrated by the argument of Dasgupta and Kanbur (2006) that philanthropy may exacerbate inequality.
} 
into our conception of social welfare. At the individual level, I have argued, potential donors can be seen as "framing" the issue in a way that makes sense of, on the one hand, their concern for the disadvantaged and, on the other, their capacity to have an impact. They understand that there are millions of potential recipients and that the contribution of one single donor to the resolution of the global problem is of infinitesimal importance, but they also see that their individual contribution can change the life of a representative individual. Suppose that we apply the same reasoning to action by governments. The UK alone cannot resolve the issue of world development. It is not infinitesimal, but it is only some $6 \frac{1}{2}$ per cent of the population of the countries that currently belong to the OECD Development Assistance Committee (DAC), which totals some 960 million. It seems reasonable for a country to shoulder its proportionate share: i.e. to represent its concern by the appropriate fraction (in the UK case $61 / 2$ per cent) of the total problem. Since the estimated number of people living below the MDG target level is 986 million (World Bank, 2007, page 65), this would mean - in round terms - each person in a DAC donor country "taking responsibility" for 1 disadvantaged person.

In this way, we may arrive at a position between, to borrow Edgeworth's phraseology, the frozen pole of national egoism and the tropical expanse of global cosmopolitanism. A country adopting such a position is retreating from the latter in three ways: (a) considering only the disadvantaged, (b) attaching a weight $\lambda$ less than 1 , and (c) considering only a share of the total proportionate to the country's potential contribution. But it would still be a more generous position than the frozen pole.

\section{Conclusions}

This paper has been concerned with the two-way interaction between individual altruism and social welfare, using this interaction to probe the foundations of welfare economics. While giving for development is only a small part of the economy of rich countries, it is one of the few direct ways in which individuals reveal information relevant to the properties of the social welfare function to be applied to global redistribution. I have suggested that, while considerations of warm glow or public goods may apply to other forms of giving, the motives for giving for development are better seen in terms of the impact on a group of representative recipients.

From this, I have drawn the following main conclusions:

- If the motives for giving for development are framed in terms of concern with the situation of representative disadvantaged recipients, then it is quite possible that this concern is non-welfarist in form; the concern may be multidimensional, and may invoke the concept of capabilities.

- These individual concerns for the disadvantaged cannot be totally ignored when formulating the social welfare function.

- If individuals evaluate the outcome of giving in a non-welfarist manner, then these should enter the social welfare function; if individuals are concerned with development in terms of capabilities, then we have to consider why we are evaluating the performance of our own society in a different way. 
- The concept of a "representative" recipient for the individual donor has a parallel at the level of the national social welfare function, suggesting how we can derive a formulation that lies between the extremes of national egoism and global cosmopolitanism. 


\section{References}

Andreoni, J, 2006, "Philanthropy" in L Gerard-Varet, S Kolm and J Ythier, editors, Handbook for Giving, Reciprocity and Altruism, Elsevier: Amsterdam.

Arrow, K J, 1981, "Optimal and voluntary income distribution" in S Rosefielde, editor, Economic Welfare and the Economics of Soviet Socialism, Cambridge University Press, Cambridge.

Atkinson, A B, 1995, Public Economics in Action, Oxford University Press, Oxford.

Atkinson, A B, 2007, "The economics of giving for overseas development", ESRC project paper.

Collard, D, 1975, “Edgeworth's propositions on altruism”, Economic Journal, vol 85: 355-360.

Dasgupta, I and Kanbur, R, 2006, "Should egalitarians expropriate philanthropists?", Working Paper 2007-03, Department of Applied Economics and Management, Cornell University.

Diamond, P A, 2006, "Optimal tax treatment of private contributions for public goods with and without warm glow preferences", Journal of Public Economics, vol 90: 897919.

Edgeworth, F Y, 1881, Mathematical Psychics, Kegan Paul, London.

Graaff, J de V, 1963, Theoretical Welfare Economics, Cambridge University Press, Cambridge.

Hammond, P J, 1987, “Altruism” in J Eatwell, M Milgate and P Newman, editors, The New Palgrave: A Dictionary of Economics, Macmillan, London.

Hochman, H M and Rodgers, J D, 1969, "Pareto optimal redistribution", American Economic Review, vol 59: 542-557.

Kanbur, R, Keen, M and Tuomala, M 2006, "Optimal non-linear income taxation for the alleviation of income poverty", European Economic Review, vol 38: 1613-1632.

Kanbur, R, Pirttilä, J and Tuomala, M, 2006, "Non-welfarist optimal taxation and behavioural public economics", Journal of Economic Surveys, vol 20: 849-868.

Kolm, S-Ch, 1969, "The optimal production of social justice" in J Margolis and $\mathrm{H}$ Guitton, editors, Public Economics, Macmillan, London.

Robertson, D H, 1954, “Utility and all what?”, Economic Journal, vol 64: 665-678.

Sen, A K, 1966, "Labour allocation in a cooperative enterprise", Review of Economic Studies, vol 33: 361-371. 
Sen, A K, 1972, "Control areas and accounting prices: An approach to economic evaluation”, Economic Journal, vol 82: 486-501.

Sen, A K, 1976, "Poverty: An ordinal approach to measurement", Econoemtrica, vol 44: 219-231.

Sen, A K, 1979, "Personal utilities and public judgements: Or what's wrong with welfare economics", Economic Journal, vol 89: 537-558.

Sen, A K, 1980, "Equality of what?” in S McMurrin, editor, Tanner Lectures on Human Values, vol 1, Cambridge University Press, Cambridge.

Sen, A K, 1985, Commodities and Capabilities, North-Holland, Amsterdam.

Smith, A, 1759, The Theory of Moral Sentiments, quotations here from 1976 edition published by Liberty Classics, Indianapolis.

Winter, S G, 1969, "A simple remark on the second optimality theorem of welfare economics", Journal of Economic Theory, vol 1: 99-103.

World Bank, 2007, Global Monitoring Report 2007, Washington, D.C. 